\title{
Viewing leisure as wasteful undermines enjoyment ${ }^{\text {th }}$
}

\author{
Gabriela N. Tonietto $^{\text {a,*, }}$, Selin A. Malkoc ${ }^{\mathrm{b}}$, Rebecca Walker Reczek ${ }^{\mathrm{c}}$, Michael I. Norton ${ }^{\mathrm{d}}$ \\ ${ }^{a}$ Assistant Professor of Marketing, Rutgers Business School-Newark and New Brunswick, Rutgers University, Newark, NJ 07102, United States of America \\ ${ }^{\mathrm{b}}$ Associate Professor of Marketing, Fisher College of Business, The Ohio State University, Columbus, OH 43210, United States of America \\ ${ }^{c}$ Berry Chair of New Technologies in Marketing, Fisher College of Business, The Ohio State University, Columbus, OH 43210, United States of America \\ ${ }^{\mathrm{d}}$ Harold M. Brierley Professor of Business Administration, Harvard Business School, Boston, MA 02163, United States of America
}

\section{A R T I C L E I N F O}

\section{Keywords:}

Leisure

Experiences

Enjoyment

Well-being

\begin{abstract}
A B S T R A C T
Engagement in leisure offers a host of benefits for mental and physical health, yet many people view leisure as wasteful and unproductive. Four studies $(n=1310)$ demonstrate that believing leisure is wasteful undermines enjoyment of enacted leisure activities. Studies 1 and 2 document that people with a general tendency to find leisure wasteful report lower enjoyment of leisure activities on average, especially terminally-motivated leisure (performed as an end in itself) compared to instrumentally-motivated leisure (performed as a means to an end). The belief that leisure is wasteful is also associated with poorer mental health outcomes, including lower reported happiness, and greater reported depression, anxiety, and stress. Establishing causality, Studies 3 and 4 show that priming the belief that leisure is wasteful or unproductive reduces enjoyment of terminally-motivated leisure activities; unfortunately, priming the belief that leisure is productive does not increase enjoyment. We discuss implications for maximizing hedonic utility and well-being.
\end{abstract}

Leisure - time away from paid work and obligations (Voss, 1967) - is meant to be enjoyed. However, various factors can undermine this enjoyment, including whether leisure is scheduled in advance (Tonietto \& Malkoc, 2016) or tracked (Etkin, 2016). Building on this prior research, we examine whether and how beliefs about leisure's value shape the enjoyment obtained during leisure activities. Leisure has a host of established benefits: It provides a sense of control in life, facilitates social relationships (Coleman \& Iso-Ahola, 1993; Glover \& Parry, 2008), lowers blood pressure (Pressman et al., 2009), and reduces the risk of depression (Iwasaki, Mackay, Mactavish, Ristock, \& Bartlett, 2006; Watson, 1988). Indeed, pleasurable experiences - from socializing to relaxing (Kahneman, Krueger, Schkade, Schwarz, \& Stone, 2004) are a source of happiness (Aaker, Rudd, \& Mogilner, 2011; Gilovich, Kumar, \& Jampol, 2015; Van Boven \& Gilovich, 2003). These benefits of leisure, however, may not accrue equally. We propose that some people hold the belief that leisure is wasteful, a belief that undermines enjoyment of enacted leisure.

To be sure, there are specific instances when leisure is unproductive and serves as a way to waste time, such as when used to procrastinate or avoid more pressing responsibilities (e.g., passing up on errands to watch TV). Indeed, when asked, 153 undergraduate students (see Supplemental Online Materials, or SOM) consistently indicated leisure is wasteful when it comes at the expense of responsibilities (see Table 1 ). ${ }^{1}$ We suggest that people may come to hold a general belief that leisure is wasteful - even when it does not interfere with goal pursuit - which then impacts their enjoyment of enacted leisure.

There are several reasons why people may come to equate leisure with wastefulness. The belief that leisure is wasteful is likely a learned association stemming from instances in which the belief is objectively true - when devoting time to leisure comes at the expense of work or necessary tasks (e.g., chores). Because it is sometimes true, people might over-apply this association, leading to a general inference that leisure is wasteful. Such overgeneralization is consistent with the operation of several lay theories, in which people over-apply a lay theory that is true in some contexts to contexts in which it is not objectively true (Haws, Reczek, \& Sample, 2017; Raghunathan, Naylor, \& Hoyer, 2006). An ever-increasing sense of time famine - the feeling of having too much to do and not enough time to do it (Perlow, 1999) - may also contribute to a general belief that leisure is wasteful. Most people, including $80 \%$ of Americans (Whillans, 2019), report time famine, which could heighten

\footnotetext{
This paper has been recommended for acceptance by Vanessa Bohns.

* Corresponding author.

E-mail addresses: gtonietto@business.rutgers.edu (G.N. Tonietto), malkoc.5@osu.edu (S.A. Malkoc), reczek.3@osu.edu (R.W. Reczek), mnorton@hbs.edu (M.I. Norton).

${ }^{1}$ Leisure during what is normally considered working hours was also considered more wasteful than leisure done during evenings or weekends (see SOM).
} 
Table 1

When leisure feels wasteful.

\begin{tabular}{lll}
\hline & Count & Percent \\
\hline When I'm procrastinating & 104 & $68 \%$ \\
When I should be working & 98 & $64 \%$ \\
When I should be taking care of other responsibilities & 98 & $64 \%$ \\
When I have a lot on my to-do list & 98 & $64 \%$ \\
When I have a goal I could be working towards & 78 & $51 \%$ \\
When I'm feeling unmotivated & 54 & $35 \%$ \\
When I know other people (e.g., my friends) are working & 30 & $20 \%$ \\
\hline
\end{tabular}

Note. Participants were given these categories and checked all that applied.

their sensitivity to alternative uses of time, thereby reinforcing a general belief that leisure is wasteful. Finally, this belief is likely enhanced by the growing emphasis on productivity (Malkoc \& Tonietto, 2019) and busyness, defined as a lack of leisure (Bellezza, Paharia, \& Keinan, 2016). Indeed, Bellezza et al. (2016) find that an overworked lifestyle is socially desirable and signals status. The prominence of busyness implies that work produces benefits, while leisure does not.

If indeed people hold a belief that leisure is wasteful, how might this belief influence their enjoyment? To believe that leisure is wasteful is to, in essence, believe that it lacks benefits, despite the evidence to the contrary (e.g., Kahneman et al., 2004; Watson, 1988). However, the literature poses mixed predictions regarding how negative beliefs about leisure's value might impact enjoyment. On the one hand, some activities that initially appear unappealing can turn out to be surprisingly pleasurable. For instance, interacting with a stranger during one's morning commute (Epley and Schroeder, 2014) and going to a movie alone (Ratner \& Hamilton, 2015) tend to be more pleasant than people expect. Further, believing in the benefits of activities is not always necessary to experience those benefits. For instance, people who do not believe in the effectiveness of enacting rituals in the face of loss nonetheless benefit from engaging in such rituals (Norton \& Gino, 2014). Both of these streams of research suggest that people may enjoy enacted leisure regardless of their belief in its value.

On the other hand, deriving greater value than expected is not the same as gleaning the full value of an activity. That is, while those who deem leisure wasteful may enjoy leisure more than they anticipate, they may nonetheless derive much less enjoyment than they would in the absence of such negative beliefs. Indeed, there is reason to expect that believing leisure is wasteful will reduce enjoyment relative to holding more positive or neutral beliefs. First, people's beliefs and expectations can become something of a self-fulfilling prophecy (Lee, Frederick, \& Ariely, 2006; Raghunathan et al., 2006; Shiv, Carmon, \& Ariely, 2005), in the way that, for example, believing that a glass of wine is more expensive (and thus higher quality) leads it to taste more flavorful (Plassmann, O'doherty, Shiv, \& Rangel, 2008). Similarly, believing leisure is wasteful, thus lacking meaningful benefits, could diminish the enjoyment of enacted leisure. Second, believing leisure is unproductive may undermine enjoyment by decreasing immersion during leisure pursuits, as immersion positively influences enjoyment (Frey, Benesch, \& Stutzer, 2007; Killingsworth \& Gilbert, 2010; Tonietto \& Barasch, in press). If one believes leisure is unproductive, they may also reasonably perceive a large opportunity cost of time - being particularly aware of other, (presumably) more productive uses of their time. As a result, those who deem leisure wasteful may be distracted from the leisure activity at hand (DeVoe \& House, 2012), experiencing less enjoyment as a result.

Endorsing the belief that leisure is wasteful, however, should not universally diminish enjoyment. Instead, negative beliefs about leisure should be especially detrimental to leisure activities that are pursued primarily for pleasure. Prior research has distinguished between terminal leisure that is immediately rewarding and instrumental leisure that serves as an instrument to achieving a longer-term goal (Botti \& McGill, 2011; Kasser \& Ryan, 1996; Kruglanski et al., 2018). ${ }^{2}$ For terminallymotivated activities, the activity and the goal are one in the same, or "fused," while for instrumentally-motivated activities, the activity is separate from the ultimate goal. Believing leisure is wasteful should be particularly detrimental for terminal leisure activities, performed with the primary motivation of pleasure, and less so for instrumental activities that are performed as a means to another (productive) purpose.

Four studies examine the effect of believing leisure is wasteful on enjoyment. The first two studies examine chronically held beliefs about leisure, demonstrating that more strongly endorsing the belief that leisure is wasteful is associated with lower enjoyment of terminal, but not instrumental, leisure activities. Further emphasizing the detrimental effects of negative beliefs about leisure, Study 2 finds that people who believe leisure is wasteful not only report lower enjoyment of leisure, but also report reduced happiness and greater depression, anxiety, and stress. Studies 3 and 4 then experimentally manipulate beliefs about leisure, replicating the detrimental effect of believing leisure is wasteful on enjoyment of terminal leisure activities. Participants primed to believe leisure is wasteful or unproductive experience a decrease in enjoyment, while those primed to believe leisure is productive do not experience a boost in enjoyment - supporting the notion that negative beliefs about leisure drive down hedonic pleasure rather than positive beliefs driving it up. Unless otherwise noted, we report how we determined our sample size, all data exclusions (if any), all manipulations, and all measures in the studies.

\section{Study 1: terminal versus instrumental leisure}

Study 1 provides an initial test of the effect of believing leisure is wasteful on enjoyment, while also examining the role of terminal versus instrumental motivations. To that end, we asked participants to recall what they did on Halloween. We chose Halloween because some common Halloween activities are relatively instrumental (e.g., taking one's child trick or treating in order to fulfill one's parental duties), while others are more terminal (e.g., attending a party for one's own amusement). We predicted that believing leisure is wasteful would be associated with reduced enjoyment of terminal activities, but that this relationship would be reduced - even eliminated - for more instrumental activities.

\subsection{Pretest}

In order to classify common Halloween activities as relatively instrumental and terminal, 50 MTurk participants $\left(M_{\text {age }}=38.00,38 \%\right.$ female) completed a pretest. Participants were provided with definitions of instrumental and terminal activities (see Appendix A) and rated whether taking kids trick or treating, handing out candy to trick or treaters, going to a party, going out to a bar/pub/club, and going to a haunted house were instrumental or terminal ( 1 = definitely instrumental, 7 = definitely terminal).

As outlined in Table 2, going to a party, to a bar/pub/club, and to a haunted house were all rated as significantly above the midpoint of the scale and were thus classified as terminal. Taking kids trick or treating and handing out candy to trick or treaters were rated as directionally

\footnotetext{
${ }^{2}$ Note that whether a particular activity is terminal or instrumental is relative and depends on the person and the situation (Kruglanski et al., 2018). For instance, people may exercise for fun (a terminal motivation; the activity is the goal) or in order to lose weight (an instrumental motivation; the activity serves the goal).
} 
Table 2

Study 1 pretest: activity classifications.

\begin{tabular}{ll}
\hline Activities & $\begin{array}{l}\text { Terminal-Instrumental } \\
(1=\text { definitely instrumental, } \\
7=\text { definitely terminal })\end{array}$ \\
\hline Going to a party & $5.32(1.68)^{* *}$ \\
Going to a bar/pub/club & $5.58(1.64)^{* *}$ \\
Going to a haunted house & $5.50(1.76)^{* *}$ \\
Taking kids trick or treating & $3.70(2.13)$ \\
Handing out candy to trick or treaters & $3.64(2.16)$ \\
\hline
\end{tabular}

$* p<.05, * * p<.01$, compared to the midpoint of the scale

Note. Numbers in parentheses represent standard deviations.

(albeit not significantly) below the midpoint, and both were rated as more instrumental than the three activities classified as terminal (all $t s$ (49) $>3.87$, all $p s<.001$ ). Accordingly, they were classified as relatively instrumental. ${ }^{3}$

\subsection{Method}

Based on an assumed small to medium effect size (Cohen's d between 0.2 and 0.5 ), 300 assignments were posted on MTurk recruiting individuals who had celebrated Halloween in some way. As a pre-screen, all potential participants first indicated whether they did anything to celebrate Halloween, and only those who answered in the affirmative were directed to the survey, yielding a final sample of 302 participants $\left(M_{\text {age }}=34.85,40.7 \%\right.$ female $) .{ }^{4,5}$ This sample had $80 \%$ power to detect a main effect or interaction with an effect size of $d=0.32$.

Participants were recruited the Monday after Halloween (November 4 , 2019). They first classified their Halloween experience into one of the pretested categories with an additional open-ended "other" option. Sixteen participants chose "other," and their responses were classified by a hypothesis-blind research assistant. For example, watching scary movies was classified as terminal. ${ }^{6}$ One hundred forty-two (47\%) participants engaged in terminal leisure, while the remaining 160 participants (53\%) engaged in relatively more instrumental leisure. Participants then indicated how much they enjoyed their Halloween experience $(0=$ not at all, $100=$ extremely). Finally, participants indicated agreement with five statements assessing the degree to which they deem leisure wasteful (e.g., "Time spent on leisure activities is often wasted time," "Leisure activities are not a productive use of time," $\alpha=$ .84; 1 = strongly disagree, 7 = strongly agree; see Appendix B). ${ }^{7}$

\subsection{Results and discussion}

Beliefs about leisure (standardized), activity type (contrast coded where terminal $=1$, instrumental $=-1$ ), and their interaction were regressed on enjoyment. Neither the main effect of activity type $(B=$

\footnotetext{
${ }^{3}$ Note that these child-oriented activities likely have both instrumental and terminal components (e.g., parents may find trick or treating with their kids both necessary as well as inherently pleasurable), which can explain why they fell in the middle of the scale.

4 Two participants completed the study without submitting their completion to MTurk, thus leading us to have two more participants than the number of assignments posted on MTurk.

5 Twelve people indicated that they did not celebrate Halloween and were redirected to the end of survey without answering any additional questions.

6 Removing the 16 participants who selected "other" from analyses does not alter the pattern or significance of the results.

7 Multiple measures unrelated to the current investigation were included for exploratory purposes. These measures were intended to explore the possible effect of texting and posting to social media on feelings of immersion and time perception and are included in the data archive. The analyses of these measures and their correlation with enjoyment are reported in the Web Appendix of a published paper (Tonietto \& Barasch, in press).
}

$0.40, S E=0.96, t(298)=0.41, p=.68, d=0.05)$ nor of beliefs about leisure were significant $(\mathrm{B}=-1.13, S E=0.96, t(298)=-1.18, p=.24$, $\mathrm{d}=-0.14)$. However the predicted interaction was significant ( $\mathrm{B}=$ $-2.45, S E=0.96, t(298)=-2.54, p=.011, d=-0.30$; see Fig. 1$)$. As expected, we found that for terminal leisure activities, greater endorsement of the belief that leisure is wasteful was associated with decreased enjoyment $(\mathrm{B}=-3.58, S E=1.41, t(298)=-2.53, p=.012, d$ $=-0.29$ ). However, there was not a significant relationship between beliefs about leisure and enjoyment for relatively instrumental leisure activities (B $=1.32, S E=1.31, t(298)=1.01, p=.32, d=0.12)$. Thus, negative beliefs about leisure uniquely undermined enjoyment of relatively terminal leisure activities. Looking at the data another way, there were two Johnson-Neyman points: On average, those low on the belief that leisure is wasteful enjoyed terminal more than instrumental activities while those high on the belief that leisure is wasteful instead enjoyed instrumental activities more. While this result is intriguing, we refrain from drawing strong conclusions as this analysis compared different activities.

As an initial test of our predictions, this study relied on a limited set of activities, while keeping the context (i.e., Halloween) constant. However, leisure captures a large umbrella of activities that vary on many dimensions, which we address in Study 2 .

\section{Study 2: leisure enjoyment and well-being}

Study 2 further examined the association between beliefs about leisure's wastefulness and enjoyment of leisure by asking participants to report how much they enjoy a variety of leisure activities. We also examined whether the relationship between beliefs about leisure and enjoyment extend to well-being. We reasoned that to the extent that enjoyment of leisure is a key precursor to leisure's benefits for mental health, then people who more strongly believe leisure is wasteful may also report reduced well-being.

\subsection{Pretest}

To determine which leisure activities to utilize in Study 2, we conducted a series of three pretests. The first pretest (Table 3, Panel A) determined whether several of the most common discretionary activities (hanging out with friends, socializing, relaxing, watching TV, hobbies, exercising, meditating, volunteering; American Time Use Survey, 2020) are considered leisure. Activities that were considered leisure were retained, and a second pretest (Table 3, Panel B) determined whether these activities are considered relatively terminal or instrumental. Finally, because leisure activities can vary on dimensions other than terminality, the third pretest examined two additional dimensions: how active and how social each activity is (Table 3, Panel C) to ensure that these dimensions were not confounded with terminality.

Based on this pretesting, hanging out with friends, socializing, relaxing, watching TV, and hobbies were classified as relatively terminal, while exercising and meditating were classified as relatively more instrumental. ${ }^{8}$ The terminal and instrumental groups included both active and passive activities, and, within activities classified as terminal, there were both solitary and social activities, confirming that terminality was not conflated with activeness or socialness.

\subsection{Method}

The methods and analyses for this study were preregistered (https://

\footnotetext{
${ }^{8}$ Note that meditating did not emerge as clearly terminal or instrumental. However, exploratory factor analyses revealed that meditating tended to load with exercising on a separate factor from the remaining activities in both Pretest 2 and in Study 2. As such, we classified meditating as relatively more instrumental.
} 


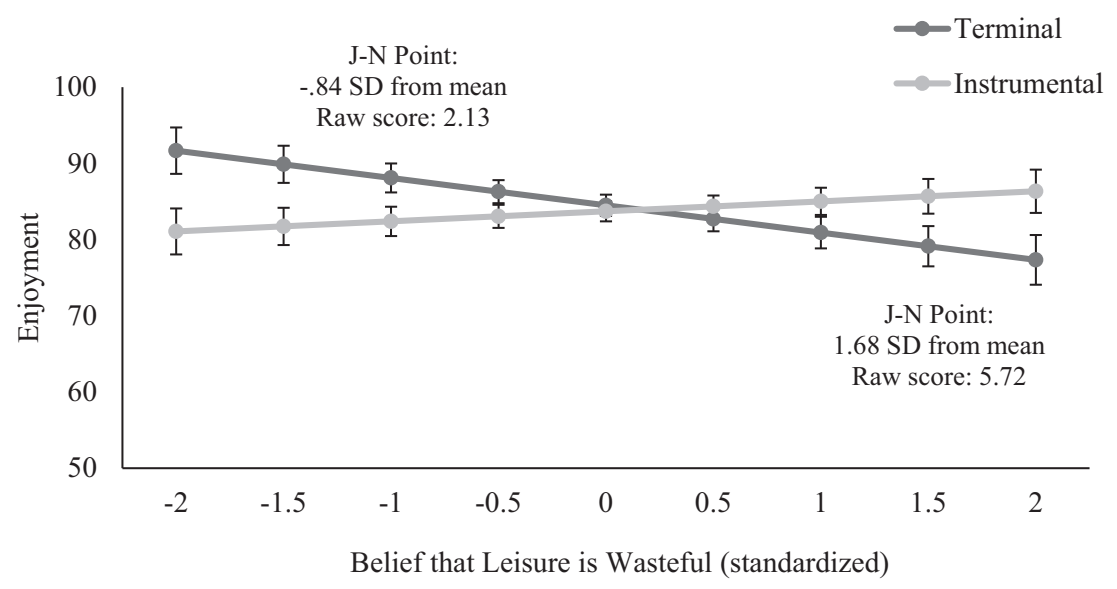

Fig. 1. Study 1: Enjoyment by Belief that Leisure is Wasteful and Type of Leisure. Note. Error bars represent \pm 1 standard error. For all means, see SOM.

aspredicted.org/jk6pm.pdf). We had access to a lab session at a large Midwestern university with a pre-specified number of participants. We stopped data collection once the session was concluded, which yielded a final sample of 199 participants ( $M_{\mathrm{age}}=20.37,44.7 \%$ female $){ }^{9}$ This sample had $80 \%$ power to detect an effect size of $r=.20(d=0.40)$.

Participants first indicated the extent to which they enjoy each of the pretested leisure activities on average $(1=$ not at all, $7=$ to a great extent, with an "N/A" option for those who do not engage in that activity ${ }^{10}$ ). Participants then completed scales assessing happiness ( $\alpha=$ .84; Lyubomirsky \& Lepper, 1999), depression ( $\alpha=.90$; Radloff, 1977), anxiety $(\alpha=.85)$ and stress $(\alpha=.90$; Lovibond \& Lovibond, 1995). Finally, participants completed the same scale assessing beliefs about leisure's wastefulness used in Study $1(\alpha=.85)$.

\subsection{Results}

As preregistered, we allowed the factor structure to dictate the treatment of different leisure activities. An exploratory factor analysis with varimax rotation and extraction based on Eigenvalues $>1$ revealed two factors, corresponding to the terminal activities (factor 1: hanging out with friends, socializing, relaxing, watching TV, hobbies) and instrumental activities (factor 2: exercising, meditating; see Table 4). As such, items loading onto a single factor were averaged together to form one scale of enjoyment of terminal activities and one scale of enjoyment of instrumental activities. Analyses of individual activities are presented in the SOM.

As in Study 1, we found that believing leisure is wasteful was associated with significantly reduced enjoyment of terminal $(r=-.16, p=$ $.022)$ but not instrumental leisure activities $(r=.06, p=.43$; see Table 5). Furthermore, we found that negative beliefs about leisure were associated with lower reported happiness $(r=-.14, p=.049)$ and greater reported depression $(r=.33, p<.001)$, anxiety $(r=.39, p<$ $.001)$, and stress $(r=.24, p=.001)$. Supporting the idea that believing leisure is wasteful may harm long term well-being by diminishing the enjoyment of terminal leisure activities, enjoyment of terminal leisure was a stronger predictor of well-being, particularly happiness and depression, than was enjoyment of instrumental leisure.

\footnotetext{
${ }^{9}$ Due to a miscommunication with the lab manager at the time the study was preregistered, a higher number of participants (up to 300) was preregistered than was set by the lab manager for study recruitment (up to 200). Recruitment could not be increased due to lab constraints, resulting in 199 participants completing the study.

10 "N/A" responses were coded as missing. "N/A" was selected by 29 participants for meditating, two participants for relaxing, and two participants for watching TV.
}

\subsection{Discussion}

Studies 1 and 2 provide convergent evidence that believing leisure is wasteful is associated with reduced enjoyment of terminally-motivated leisure activities. Importantly, the group of terminal activities in Study 2 included both passive and active leisure, as well as both social and solitary leisure. Thus, this study provides evidence that the motivation behind the leisure activity - whether pursued primarily for pleasure or as a means to an end - determines the effect of negative beliefs about leisure on enjoyment, rather than how active or social the activity is.

Study 2 also demonstrates that negative beliefs about leisure are associated with reduced happiness and well-being. To further examine the generality of this finding, we ran an additional study (reported in the SOM) using subsamples collected from three countries that vary in their norms towards work and leisure as indicated by Hofstede's (2011) industry-indulgence dimension: The U.S. $(n=150)$, France $(n=159)$, and India $(n=153)$. Cultures high on this dimension (e.g., India) are more work-oriented and have social norms that emphasize work and a suppression of gratification. Cultures low on this dimension (e.g., France) instead have social norms that are less restrictive of enjoying life and having fun (Minkov, 2013). While the distribution of beliefs about leisure's wastefulness varied across countries, we found that believing leisure is wasteful was associated with higher reported depression, anxiety, and stress in all three. Thus, in a variety of populations, including undergraduate students and adults from diverse cultures, believing leisure is wasteful was associated with reduced well-being, where the reduced enjoyment of leisure may be one factor contributing to this negative relationship.

Due to the correlational nature of the studies so far, it is not possible to conclude that it is the belief that leisure is wasteful that decreases enjoyment (and not vice versa). The remaining studies experimentally test the detrimental effect of believing leisure is wasteful on relatively terminal leisure activities by manipulating, rather than measuring, beliefs about leisure.

\section{Study 3: priming beliefs about leisure's value}

This study examined whether priming the belief that leisure is wasteful or unproductive decreases enjoyment of a leisure activity relative to priming the belief that leisure is productive or a control (i.e., non-leisure prime). We included both a condition describing leisure as "wasteful" and a separate condition describing leisure as "unproductive" in order to test robustness to the negative connotation of the descriptor, where "wasteful" may have a particularly strong negative connotation. Because "wasteful" and "unproductive" are often used synonymously and both amount to a belief that leisure lacks value, we predicted both would decrease enjoyment of leisure relative to believing leisure is productive or a baseline control. 
Table 3

Study 2 pretests: activity classifications.

\begin{tabular}{|c|c|c|c|}
\hline \multicolumn{4}{|c|}{ Panel A. Pretest $1(n=240)$} \\
\hline Activities & \multicolumn{3}{|l|}{$\begin{array}{l}\text { Leisure } \\
(1=\text { definitely } \\
\text { not leisure, } \\
7=\text { definitely } \\
\text { leisure })\end{array}$} \\
\hline $\begin{array}{l}\text { Hanging out with } \\
\text { friends }\end{array}$ & \multicolumn{3}{|l|}{$5.68(1.58)^{* * *}$} \\
\hline Relaxing & \multicolumn{3}{|l|}{$5.97(1.56)^{* *}$} \\
\hline Watching TV & \multicolumn{3}{|l|}{$6.07(1.35)^{* *}$} \\
\hline Hobbies & \multicolumn{3}{|l|}{$5.29(1.75)^{* * *}$} \\
\hline Exercising & \multicolumn{3}{|l|}{$4.32(2.00)^{*}$} \\
\hline Meditating & \multicolumn{3}{|l|}{$4.85(1.89)^{* * *}$} \\
\hline Volunteering $^{\mathrm{a}}$ & \multicolumn{3}{|l|}{$3.88(1.79)$} \\
\hline \multicolumn{4}{|c|}{ Panel B. Pretest $2(n=130)$} \\
\hline Activities & $\begin{array}{l}\text { Terminal } \\
(1=\text { not at all, } \\
7=\text { to a great } \\
\text { extent })\end{array}$ & $\begin{array}{l}\text { Instrumental } \\
(1=\text { not at all, } \\
7=\text { to a great } \\
\text { extent })\end{array}$ & $\begin{array}{l}\text { Paired-samples } \\
\text { comparisons }\end{array}$ \\
\hline $\begin{array}{l}\text { Hanging out with } \\
\text { friends }\end{array}$ & $5.17(1.79)^{* *}$ & $4.24(1.83)$ & $\begin{array}{l}t(130)=4.41, p< \\
.001\end{array}$ \\
\hline Socializing ${ }^{\mathrm{b}}$ & $5.11(1.59)^{* *}$ & $4.56(1.53)^{* * *}$ & $\begin{array}{l}t(130)=3.01, p= \\
.003\end{array}$ \\
\hline Relaxing & $5.24(1.68)^{* *}$ & $4.40(1.84)^{*}$ & $\begin{array}{l}t(130)=3.96, p< \\
.001\end{array}$ \\
\hline Watching TV & $4.98(1.75)^{* *}$ & $3.57(1.82)^{* *}$ & $\begin{array}{l}t(130)=6.53, p< \\
.001\end{array}$ \\
\hline Hobbies & $5.20(1.60)^{* *}$ & $4.71(1.65)^{* *}$ & $\begin{array}{l}t(130)=2.70, p= \\
.008\end{array}$ \\
\hline Exercising & $4.83(1.84)^{* * *}$ & $5.27(1.63)^{* *}$ & $\begin{array}{l}t(130)=-2.39, p= \\
.018\end{array}$ \\
\hline Meditating & $4.74(1.75)^{* *}$ & $4.65(1.68)^{* *}$ & $\begin{array}{l}t(130)=0.43, p= \\
.67\end{array}$ \\
\hline \multicolumn{4}{|c|}{ Panel C. Pretest $3(n=324)$} \\
\hline Activities & $\begin{array}{l}\text { Active-Passive } \\
(1=\text { very passive, } \\
7=\text { very active })\end{array}$ & $\begin{array}{l}\text { Social-Solitary } \\
(1=\text { totally } \\
\text { solitary, } \\
7=\text { totally } \\
\text { social })\end{array}$ & \\
\hline $\begin{array}{l}\text { Hanging out with } \\
\text { friends }\end{array}$ & $5.43(1.26)^{* * *}$ & $6.53(0.95)^{* *}$ & \\
\hline Relaxing & $2.45(1.88)^{* *}$ & $2.69(1.45)^{* *}$ & \\
\hline Watching TV & $2.55(1.69)^{* *}$ & $3.19(1.42)^{* *}$ & \\
\hline Hobbies & $5.17(1.32)^{* * *}$ & $4.00(1.49)$ & \\
\hline Exercising & $6.26(1.31)^{* * *}$ & $3.47(1.44)^{* *}$ & \\
\hline Meditating & $3.22(1.93)^{* *}$ & $1.65(1.26)^{* *}$ & \\
\hline
\end{tabular}

$* p<.05, * * p<.01$ compared to the midpoint of the scale

a Although researchers have coded volunteering as a form of active leisure (e. g., Smeets, Whillans, Bekkers, \& Norton, 2020), volunteering was not considered leisure in this population and, as such, was not included in pretests 2 and 3.

b Due to a survey error, socializing was not included in pretests 1 and 3 .

Table 4

Study 2: factor loadings of exploratory principal component analysis.

\begin{tabular}{lll}
\hline Components & 1 & 2 \\
\hline Activities & & \\
Hanging out with friends & .80 & .27 \\
Socializing & .75 & .24 \\
Relaxing & .78 & .05 \\
Watching TV & .69 & -.18 \\
Hobbies & .76 & .15 \\
Exercising & .38 & .71 \\
Meditating & -.09 & .83 \\
\hline
\end{tabular}

\subsection{Pretest}

We conducted a pretest to confirm that the activity used in Study 3 was considered to be leisure. As part of a lab session, 130 undergraduate participants $\left(M_{\text {age }}=22.17,47 \%\right.$ female $)$ watched the funny cat video
Table 5

Study 2: correlation matrix.

\begin{tabular}{|c|c|c|c|c|c|c|c|}
\hline & 1 & 2 & 3 & 4 & 5 & 6 & 7 \\
\hline $\begin{array}{l}\text { 1. Belief that } \\
\text { Leisure is } \\
\text { Wasteful }\end{array}$ & - & & & & & & \\
\hline $\begin{array}{l}\text { 2. Enjoyment of } \\
\text { Terminal } \\
\text { Leisure } \\
\text { Activities }\end{array}$ & $-.16^{*}$ & - & & & & & \\
\hline $\begin{array}{l}\text { 3. Enjoyment of } \\
\text { Instrumental } \\
\text { Leisure } \\
\text { Activities }\end{array}$ & .06 & $.26^{* *}$ & - & & & & \\
\hline 4. Happiness & $-.14 *$ & $.41^{* *}$ & $.17^{*}$ & - & & & \\
\hline 5. Depression & $.33^{* *}$ & $--.24 * *$ & -.02 & $-.53^{* *}$ & - & & \\
\hline 6. Anxiety & $.39^{* *}$ & --.10 & -.03 & $-.26^{* *}$ & $.69^{* *}$ & - & \\
\hline 7. Stress & $.24^{* *}$ & -.09 & .03 & $-.34^{* *}$ & $.76^{* *}$ & $.76^{* *}$ & - \\
\hline
\end{tabular}

used in the main study and then indicated whether doing so was work or leisure and a chore or fun activity ( $1=$ definitely work/a chore, $7=$ definitely leisure/a fun activity; $r=.67, p<.001$ ). Confirming that watching the video is considered leisure, this activity was rated significantly above the scale midpoint $(M=4.87, S D=1.70, t(129)=5.84, p$ $<.001, d=0.51)$.

\subsection{Method}

The methods and analyses for this study were preregistered (https:// aspredicted.org/bv3vd.pdf). We had access to a lab session at two large Northeastern university campuses, each with a pre-specified number of participants. We stopped data collection once the session was concluded at both campuses, which yielded a final sample of 458 participants $\left(M_{\text {age }}=21.59,57.4 \%\right.$ female). This sample had $80 \%$ power to detect an effect size of $d=0.31$ for the omnibus test and $d=0.37$ for individual pairwise comparisons. The study followed a four-cell (leisure is wasteful vs. leisure is unproductive vs. leisure is productive vs. control) betweensubjects design.

Participants were told that they would read and evaluate an article (in line with prior work using fabricated news articles to temporarily prime various beliefs; Feinberg \& Willer, 2011; Wisman \& Goldenberg, 2005). The articles were designed to look like New York Times articles and either described leisure as wasteful (e.g., it reduces goal achievement and learning), unproductive (utilizing the same descriptions as in the wasteful condition, but replacing the word "wasteful" with "unproductive" throughout), productive (e.g., it helps manage stress and increases energy), or discussed coffee makers (control condition; see Appendix C). In order to maintain the cover story, after reading the article, participants indicated how well-written, readable, and coherent the article was ( $1=$ not at all, 7 = extremely; see SOM for analyses of this scale). Next, participants read that in order to take a short break from the study, they would watch a video. They then watched the pretested video (Best Funny Cat Videos 2019) and indicated enjoyment using two items: "How much did you enjoy watching the video?" and "How much fun was it to watch the video?" on slider scales $(0=$ not at all, $100=$ extremely). ${ }^{11}$ The two items were averaged together to form one measure of enjoyment $(r=.95, p<.001)$. Finally, participants completed the 10-item short-form Positive and Negative Affect Schedule (Thompson, 2007) by indicating the extent to which they felt five positive $(\alpha=.90)$ and five negative feelings ( $\alpha=.92)$ while watching the video ( $1=$ very slightly/not at all, $5=$ extremely).

\footnotetext{
$\overline{11}$ Two items were used in this study in order to increase reliability. However, analyses using only the enjoyment item yield similar results.
} 


\subsection{Results and discussion}

An ANOVA revealed a significant effect of the beliefs about leisure manipulation on enjoyment $(F(3,454)=2.65, p=.049, d=0.26$; see Fig. 2). As expected, enjoyment did not differ between the wasteful ( $M$ $=55.11, S D=36.44)$ and unproductive $(M=53.88, S D=35.52)$ conditions $(t(225)=0.26, p=.80, d=0.03)$. More importantly, participants primed to believe leisure is wasteful enjoyed watching the video marginally less than those primed that leisure is productive $(M=62.95$, $S D=32.63 ; t(229)=-1.72, p=.086, d=-0.23)$ and those in the control condition $(M=63.81, S D=31.02 ; t(226)=-1.94, p=.053, d=$ $-0.26)$. Likewise, participants primed to believe leisure is unproductive enjoyed the leisure experience significantly less than those primed that leisure is productive $(t(228)=-2.02, p=.045, d=-0.27)$ and those in the control condition $(t(225)=-2.24, p=.026, d=-0.30)$. The productive and control conditions did not differ from each other $(t(229)=$ $0.21, p=.84, d=-0.03)$.

We also ran regression analyses utilizing contrast coding (see Table 6). We found that priming the belief that leisure is wasteful or unproductive decreased enjoyment and positive affect compared to the other two conditions. There were no significant effects on negative affect. $^{12}$

Study 3 provides causal evidence that believing leisure lacks value (i. e., is wasteful or unproductive) decreases enjoyment of terminallymotivated leisure. Moreover, the results provide evidence for the direction of the effect: There is a detriment from believing leisure is wasteful rather than a boost from believing leisure is productive. An additional supplemental study (reported in the SOM; $n=189$ undergraduate participants) was conducted to further corroborate this directional effect while also testing robustness to an additional leisure activity: playing Tetris. We once again found that priming the belief that leisure is wasteful significantly reduced enjoyment, this time of playing a video game, compared to priming the belief that leisure is productive or a control. As in Study 3, while there was a detriment to believing leisure is wasteful, we did not observe a benefit to believing leisure is productive.

While providing promising experimental evidence and testing robustness to more versus less negative descriptors, the manipulations used in Study 3 framed wastefulness and lack of productivity as undesirable. It is therefore possible that participants reported lower enjoyment because they read that leisure is "bad," consistent with a demand effect. In Study 4, we address this by utilizing a prime that positively framed leisure's wastefulness.

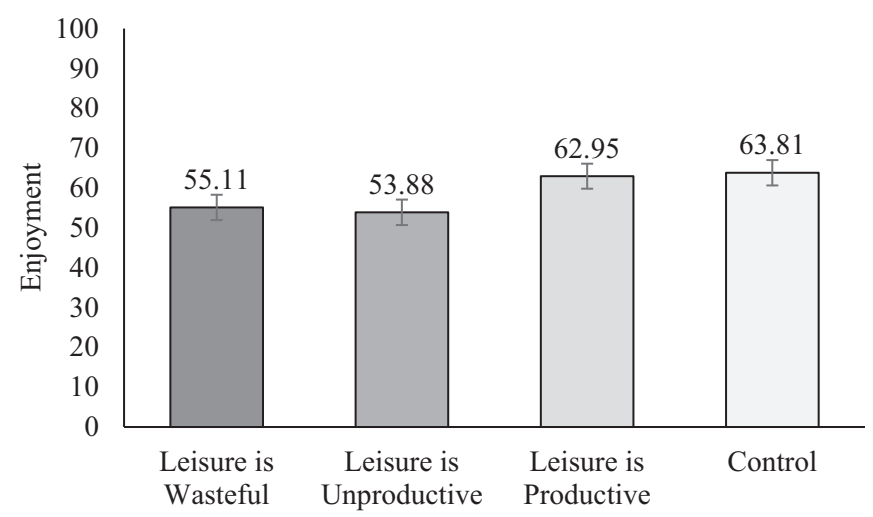

Fig. 2. Study 3: Enjoyment by Beliefs about Leisure Prime. Note. Error bars represent \pm 1 standard error.

\footnotetext{
$\overline{12}$ For all pairwise comparisons for positive and negative affect, see SOM.
}

Table 6

Study 3: regression output.

\begin{tabular}{|c|c|c|c|}
\hline & Enjoyment & $\begin{array}{l}\text { Positive } \\
\text { Affect }\end{array}$ & $\begin{array}{l}\text { Negative } \\
\text { Affect }\end{array}$ \\
\hline Constant & $58.94(1.59)$ & $\begin{array}{l}2.42 \\
(0.05)\end{array}$ & $1.43(0.04)$ \\
\hline $\begin{array}{l}\text { Contrast } 1 \\
\quad \text { Wasteful }=1, \text { Unproductive }=1 \text {, } \\
\text { Productive }=-1, \text { Control }=-1 \text { ) }\end{array}$ & $\begin{array}{l}-4.44 \\
(1.59)^{* *}\end{array}$ & $\begin{array}{l}-0.11 \\
(0.05)^{*}\end{array}$ & $0.04(0.04)$ \\
\hline $\begin{array}{l}\text { Contrast } 2 \\
\quad \text { Wasteful }=-1, \text { Unproductive }=1 \text {, } \\
\text { Productive }=0, \text { Control }=0 \text { ) }\end{array}$ & $\begin{array}{l}-0.62 \\
(2.25)\end{array}$ & $\begin{array}{l}-0.02 \\
(0.07)\end{array}$ & $0.00(0.05)$ \\
\hline $\begin{array}{l}\text { Contrast } 3 \\
\text { (Wasteful }=0, \text { Unproductive }=0 \text {, } \\
\text { Productive }=1, \text { Control }=-1 \text { ) }\end{array}$ & $\begin{array}{l}-0.43 \\
(2.24)\end{array}$ & $\begin{array}{l}-0.10 \\
(0.07)\end{array}$ & $\begin{array}{l}-0.03 \\
(0.05)\end{array}$ \\
\hline
\end{tabular}

Note. Numbers in parentheses represent standard errors.

* $p<.05$.

$p<.01$

\section{Study 4: positively framing leisure's wastefulness}

The purpose of Study 4 was to ensure that the detrimental effect of the leisure is wasteful prime observed in Study 3 is not reliant on the negative framing of wastefulness. Thus, in Study 4, we altered the prime to have a more positive overall tone, describing leisure as wasteful, and framing this wastefulness as desirable with multiple beneficial outcomes (utilizing the benefits from the leisure is productive prime in Study 3).

\subsection{Method}

We had access to a lab session at a large Northeastern university with a pre-specified number of participants. We stopped data collection once the session was concluded, which yielded a final sample of 351 undergraduate students $\left(M_{\text {age }}=20.25,51 \%\right.$ female). This sample had $80 \%$ power to detect an effect size of $d=0.30$. As in Study 3, participants were told that they would be evaluating a New York Times article. They were then randomly assigned to one of two between-subjects conditions (leisure is wasteful vs. control). The leisure is wasteful article was altered to have a more positive tone and argued that leisure is wasteful, but that wastefulness is what makes leisure beneficial to individuals (see Appendix D). The control article was the same as in Study 3. Participants then indicated how well-written, readable, and coherent the article was in order to maintain the cover story for the article. Next, participants watched the same video and responded to the same two items assessing enjoyment $(r=.92, p<.001)$ as in Study 3 .

\subsection{Results and discussion}

We replicated the core effect, such that priming the belief that leisure is wasteful significantly reduced enjoyment $(M=59.21, S D=32.75)$ compared to the control condition $(M=67.14, S D=28.46, t(349)=$ $-2.42, p=.016, d=-0.26)$. Thus, believing leisure is wasteful undermined the hedonic utility of the leisure experience, even when wastefulness was framed as positive and even necessary for productivity.

Taken together, Studies 3 and 4 demonstrate that believing leisure lacks value causes terminally-motivated leisure experiences to be less enjoyable: Priming the belief that leisure is wasteful or unproductive significantly reduced enjoyment of a leisure experience.

\section{General discussion}

Although leisure and positive experiences are important contributors to happiness and well-being (Kahneman et al., 2004; Van Boven \& Gilovich, 2003), we demonstrate that some people believe that leisure is wasteful - to their own detriment. Four studies establish that believing leisure is wasteful undermines the hedonic benefits of leisure pursuits. 
Studies 1 and 2 document that people who believe leisure is wasteful report lower enjoyment of leisure activities, particularly those that are relatively terminal, or performed predominantly in the pursuit of pleasure, as opposed to those leisure activities that also serve an instrumental purpose. Further, Study 2 (and a supplemental study) shows that negative beliefs about leisure are also associated with reduced happiness and well-being, an effect observed in samples that varied in age and country of origin. Finally, Studies 3 and 4 (and a supplemental study) demonstrate that priming the belief that leisure is wasteful or unproductive reduces enjoyment of terminally-motivated leisure.

Our research makes several contributions to the literature. First, while beliefs about work and busyness (Bellezza et al., 2016; McHoskey, 1994) may impact the choice to engage in leisure, we show that beliefs about leisure can influence the enjoyment of enacted leisure. In so doing, we contribute to the limited research examining factors that undermine enjoyment of leisure activities (Etkin, 2016; Tonietto \& Malkoc, 2016). Second, we build on previous research examining post-consumption regret about indulgence and forbearance (Haws \& Poynor, 2008; Kivetz \& Keinan, 2006). Our results suggest that regret about forgoing leisure may not extend to those who believe that leisure is wasteful, because they enjoy leisure less. In this sense, counterintuitively, avoiding leisure may in some cases be a rational strategy for maximizing hedonic utility. However, the results of Study 2 and our supplemental study indicate that this may come at the expense of long-term wellbeing, where those who experience less pleasure from leisure report reduced happiness and greater depression, anxiety, and stress. As such, we also contribute to the literature on happiness from experiences (Gilovich et al., 2015; Van Boven \& Gilovich, 2003; West, Mogilner, \& DeVoe, 2021). Happiness, it seems, may be driven not only by whether people engage in leisure, but whether they find value in their leisure.

Our experimental studies establish that the observed effects are driven by a detriment from believing leisure is wasteful rather than a benefit from believing leisure is productive. While priming the belief that leisure is productive did not increase enjoyment relative to a control, future research might work to uncover other interventions to alleviate the negative impact of believing leisure is wasteful. For example, perhaps framing leisure as goal-consistent would allow people with negative beliefs about leisure to perceive leisure as more instrumental, thus mitigating the observed effects. Further, while we examined culture in a supplemental study, future research could explore other demographic factors such as gender (Giurge, Whillans, \& West, 2020) and income (Smeets et al., 2020), both of which impact how people experience and spend their time. Examination of gender might be particularly impactful, where greater temporal demands and fewer opportunities for leisure exacerbate gender inequality (Giurge et al., 2021; Robinson \& Godbey, 1998). ${ }^{13}$ One limitation of our work is that we relied on self-reports of enjoyment and subjective well-being at a single point in time rather than longitudinal data assessing the relationship between beliefs about leisure, time spent on various leisure activities, and well-being over time. Indeed, beliefs about leisure may have other, important behavioral outcomes that shape people's lives and experiences, which future research might explore. For instance, those who deem leisure wasteful might be particularly reluctant to engage in leisure, potentially because they enjoy it less. Alternatively, rather than decreasing the amount of time spent on leisure, beliefs about leisure's wastefulness may instead drive people's choices of different types of leisure, with those who deem leisure wasteful potentially opting for more productive or instrumental leisure activities on average.

\section{Open practices}

This article earned Open Materials, Open Data, and Preregistered badges for transparent practices. All materials and data are available on a permanent third-party archive: https://osf.io/v8frw/?view_only $=505$ e488fe5da46658cfd9573e3ef357f. Studies 2 (https://aspredicted.org/ jk6pm.pdf) and 3 (https://aspredicted.org/bv3vd.pdf) were preregistered. For both studies, the plan was registered prior to the collection of the data. No additional registrations were created for the studies other than the ones reported. No additional analyses that deviated from the registered plan were conducted, and all analyses described in the registered plan are reported either in-text or in the Supplemental Online Materials.

\section{Appendix A}

Pretests: Definitions of Terminal and Instrumental Leisure

Activities can be divided into two categories: instrumental and terminal.

Instrumental activities are performed as a means to an end. For example, a leisure activity might be performed primarily in pursuit of a goal or to fulfill one's responsibilities.

Terminal activities are performed as an end in themselves. For example, a leisure activity might be performed for one's own pleasure or to fulfill one's own wants or desires.

\section{Appendix B}

We are interested in your thoughts and opinions about leisure activities. Leisure activities are those that are intrinsically motivated and fun and are done in the pursuit of pleasure, enjoyment, and/or relaxation. Such tasks include playing, relaxing, watching TV, reading, socializing, etc. Please indicate the extent to which you agree with each of the following statements about leisure activities and the time spent on such activities. (Scale: $1=$ Strongly disagree, 7 = Strongly agree)

1. Time spent on leisure activities is often wasted time

2. People who engage in leisure tasks a lot have too much free time on their hands

3. Most leisure activities are a way to burn time

4. People should strive to make time spent on leisure more productive

5. Leisure activities are not a productive use of time

\footnotetext{
$\overline{13}$ Interested readers can find exploratory analyses of gender and age effects for each study in the SOM. We refrain from interpreting the results as our studies were not designed to test interactions with demographic variables and may thus be underpowered.
} 


\section{Appendix C}

Study 3 Article Primes

Leisure is wasteful condition:

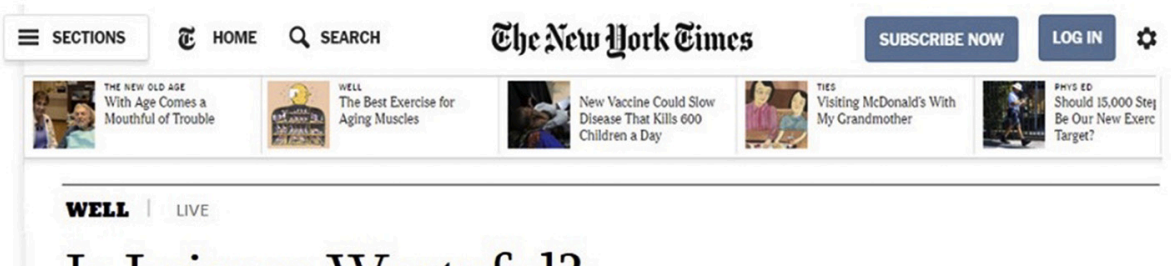

Is Leisure Wasteful?

A recent poll says "yes."

BY JORDAN KENNEDY MARCH 4, 2019

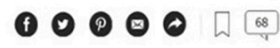

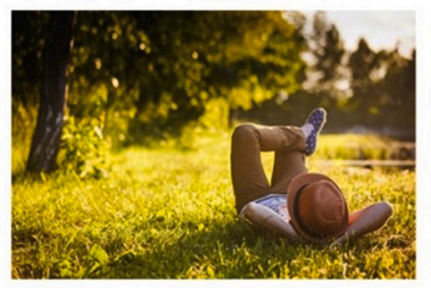

Is leisure wasteful? A group of academic researchers were interested in this question and took it to the polls. These psychologists asked everyday people what they thought about leisure time. Overwhelmingly, people appeared to think about leisure time as a wasteful way to spend time.

This is in line with decades of research in psychology showing that leisure, in many ways, is wasteful. One big reason: leisure is time not spent pursuing our goals. Research shows, for example, that participating in leisure and recreation reduces goal achievement and learning. Goal achievement and learning are important for both physical and mental health.

Looking at the responses people gave when asked about their own leisure experiences shows that we have a fairly good intuition about leisure. Several people pointed to the productivity costs of leisure:

"You don't work on your goals while partaking in leisure time."

"Leisure doesn't stimulate your brain. Also, we could be spending this precious time improving ourselves - learning something."

"I often wonder why I spend time on leisure. I accomplish nothing and just get lazy."

These are just a few examples people came up with when asked about leisure.

So to answer the question is leisure wasteful, it seems research and intuition both say "yes." 
Leisure is unproductive condition

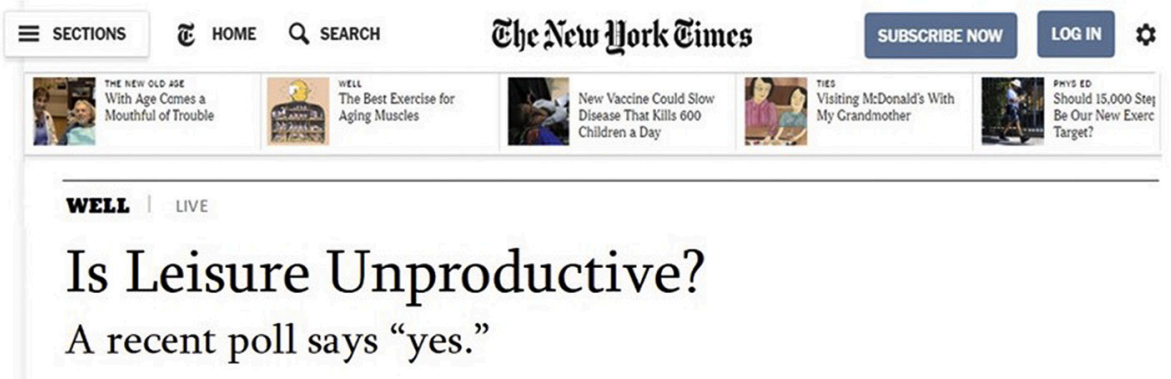

By JORDAN KENNEDY MARCH 4,2019

$\bullet \circ \odot \odot \odot$

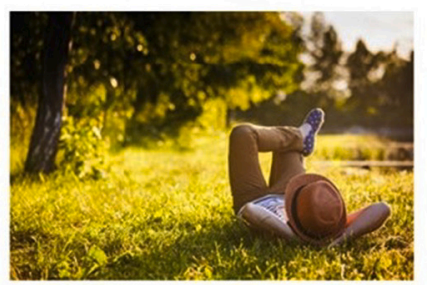

Is leisure unproductive? A group of academic researchers were interested in this question and took it to the polls. These psychologists asked everyday people what they thought about leisure time. Overwhelmingly, people appeared to think about leisure time as an unproductive way to spend time.

This is in line with decades of research in psychology showing that leisure, in many ways, is unproductive. One big reason: leisure is time not spent pursuing our goals. Rescarch shows, for cxamplc, that participating in lcisurc and recreation reduces goal achievement and learning. Goal achievement and learning are important for both physical and mental health.

Looking at the responses people gave when asked about their own leisure experiences shows that we have a fairly good intuition about leisure. Several people pointed to the productivity costs of leisure:

"You don't work on your goals while partaking in leisure time."

"Leisure doesn't stimulate your brain. Also, we could be spending this precious time improving ourselves - learning something."

"I often wonder why I spend time on leisure. I accomplish nothing and just get lazy."

These are just a few examples people came up with when asked about leisure.

So to answer the question is leisure unproductive, it seems research and intuition both say "yes." 


\section{Appendix D}

Leisure is productive condition

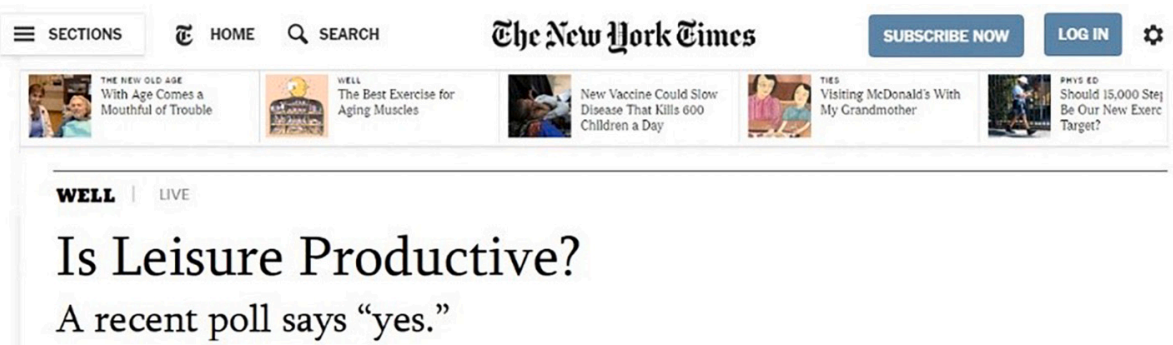

By OORDAN KENNEDY JANUARY 24, 2019

1000

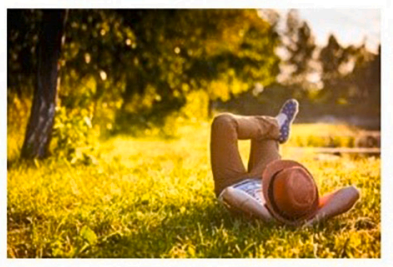

Is leisure productive? A group of academic researchers were interested in this question and took it to the polls. These psychologists asked everyday people what they thought about leisure time. Overwhelmingly, people appeared to think about leisure as a productive way to spend time.

This is in line with decades of research in psychology showing that leisure, in many ways, is productive. One big reason: it's vital for health and happiness. Research shows, for example, that participating in leisure and recreation helps us to better manage stress and keeps us energized. Relaxation and fun, it turns out, are important for both physical and mental health.

Looking at the responses people gave when asked about their own leisure experiences shows that we have a fairly good intuition about leisure. Several people pointed to the health aspects of leisure:

"It reduces stress and allows you to not be so tense."

"Down time restores your energy."

"Leisure allows the core parts of our brain to take a break and rejuvenate so that you feel fresh when you return to more strenuous tasks."

These are just a few examples people came up with when asked about leisure.

So to answer the question is leisure productive, it seems research and intuition both say "yes." 


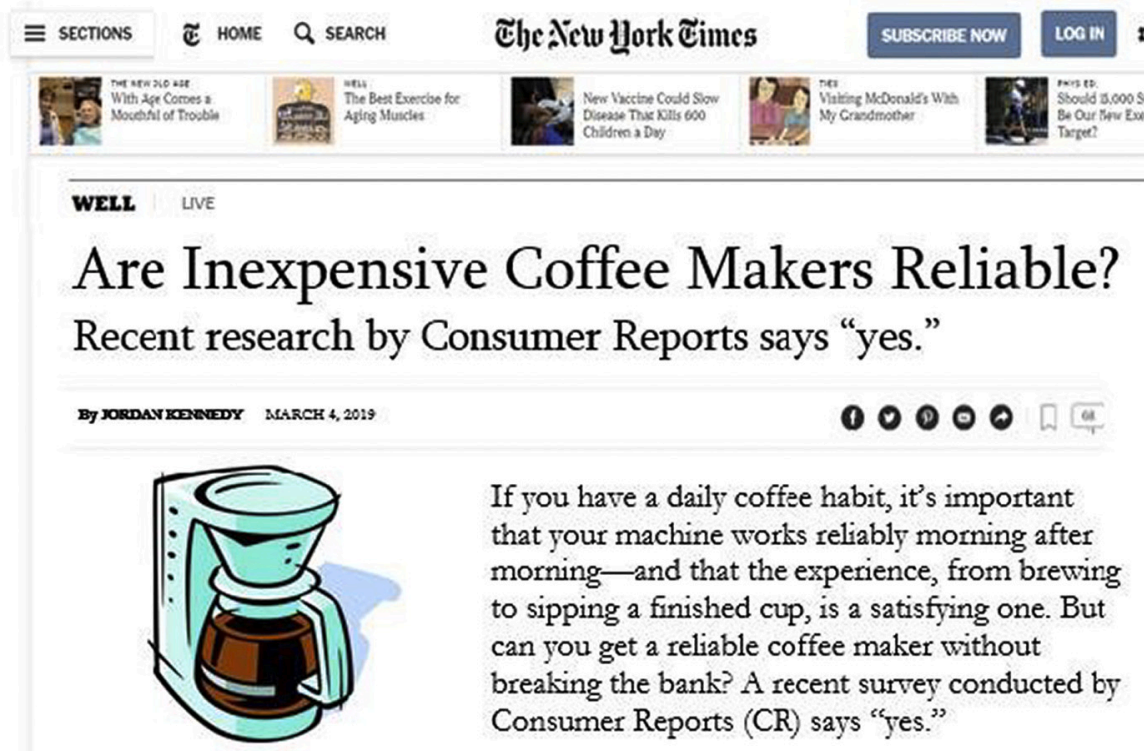

The survey asked members to evaluate over 80,000 coffee makers, covering almost 30 brands. Drip machines, especially more affordable plastic models, can sometimes feel cheap and disposable. But according to their survey, these machines, as a category, are quite reliable. Just about every major brand received a moderate to highly favorable rating for predicted reliability.

Affordable household names like Cuisinart, Black+Decker, Hamilton Beach, KitchenAid, Krups, and Mr. Coffee all scored surprisingly well on predicted reliability and customer satisfaction. However, for many of these brands, these high scores were limited to drup cottee machines. Unce we get into single-serve coffee, several of these big name brands start to underperform compared to their pricier competitors. This was the case for all except Cuisinart, which received ratings on its pod coffee maker that rivaled the ultra-popular Keurig machines.

So whether you are looking for a full pot or a single-serve, $C R$ research finds that even relatively inexpensive models can get the job done reliably. 
Appendix D Study 4 Leisure is Wasteful Prime

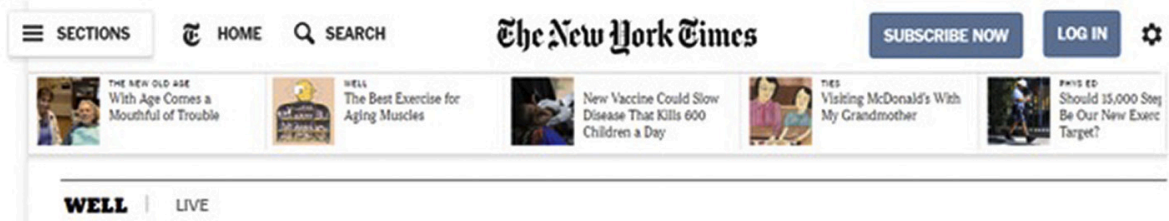

\section{Is Leisure Wasteful?}

Yes, and that's what makes leisure beneficial.

By JORDAN SOENTIXY MARCH 4, 2019

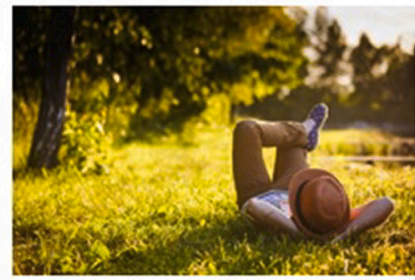

$\circ \circ \odot \circ \odot$

Is leisure wasteful? A group of academic researchers were interested in this question and took it to the polls. These psychologists asked everyday people what they thought about leisure time. Overwhelmingly, people appeared to think about leisure time as a wasteful way to spend time, but that's a good thing.

This is in line with decades of research in psychology showing that leisure, in many ways, is unproductive. But wastefulness is good: it's vital for health and happiness. Research shows, for example, that participating in leisure and recreation helps us to better manage stress and keeps us energized. Leisure and idle time, it turns out, are important for both physical and mental health.

Looking at the responses people gave when asked about their own leisure experiences shows that we have a fairly good intuition about leisure and how the wastefulness of leisure can be a good thing. Several people pointed to the health aspects of leisure:

"It reduces stress and allows you to not be so tense."

"Down time restores your energy."

"Leisure allows the core parts of our brain to take a break and rejuvenate so that you feel fresh when you return to more strenuous tasks."

These are just a few examples people came up with when asked about leisure.

So to answer the question is leisure wasteful, it seems research and intuition both say "yes," but that's what makes it beneficial for us.

\section{Appendix E. Supplementary data}

Supplementary data to this article can be found online at https://doi.org/10.1016/j.jesp.2021.104198.

\section{References}

Aaker, J. L., Rudd, M., \& Mogilner, C. (2011). If money does not make you happy, consider time. Journal of Consumer Psychology, 21(2), 126-130.

American Time Use Survey Summary. (2020, June 25). Retrieved March 1, 2021, from https://www.bls.gov/news.release/atus.nr0.htm.

Bellezza, S., Paharia, N., \& Keinan, A. (2016). Conspicuous consumption of time: When busyness and lack of leisure time become a status symbol. Journal of Consumer Research, 44(1), 118-138.

Botti, S., \& McGill, A. L. (2011). The locus of choice: Personal causality and satisfaction with hedonic and utilitarian decisions. Journal of Consumer Research, 37(6), 1065-1078.
Coleman, D., \& Iso-Ahola, S. E. (1993). Leisure and health: The role of social support and self-determination. Journal of Leisure Research, 25(2), 111-128.

DeVoe, S. E., \& House, J. (2012). Time, money, and happiness: How does putting a price on time affect our ability to smell the roses? Journal of Experimental Social Psychology, 48(2), 466-474.

Etkin, J. (2016). The hidden cost of personal quantification. Journal of Consumer Research, 42(6), 967-984.

Epley, N., \& Schroeder, J. (2014). Mistakenly seeking solitude. Journal of Experimental Psychology: General, 143(5), 1980.

Feinberg, M., \& Willer, R. (2011). Apocalypse soon? Dire messages reduce belief in global warming by contradicting just-world beliefs. Psychological Science, 22(1), 34-38.

Frey, B. S., Benesch, C., \& Stutzer, A. (2007). Does watching TV make us happy? Journal of Economic Psychology, 28(3), 283-313. 
Gilovich, T., Kumar, A., \& Jampol, L. (2015). A wonderful life: Experiential consumption and the pursuit of happiness. Journal of Consumer Psychology, 25(1), 152-165.

Giurge, L. M., Whillans, A. V., \& West, C. (2020). Why time poverty matters for individuals, organisations and nations. Nature Human Behaviour, 4(10), 993-1003.

Glover, T. D., \& Parry, D. C. (2008). Friendships developed subsequent to a stressful life event: The interplay of leisure, social capital, and health. Journal of Leisure Research 40(2), 208-230.

Haws, K. L., \& Poynor, C. (2008). Seize the day! Encouraging indulgence for the hyperopic consumer. Journal of Consumer Research, 35(4), 680-691.

Haws, K. L., Reczek, R. W., \& Sample, K. L. (2017). Healthy diets make empty wallets: The healthy= expensive intuition. Journal of Consumer Research, 43(6), 992-1007.

Hofstede, G. (2011). Dimensionalizing cultures: The Hofstede model in context. Online Readings in Psychology and Culture, 2(1), 8.

Iwasaki, Y., Mackay, K. J., Mactavish, J. B., Ristock, J., \& Bartlett, J. (2006). Voices from the margins: Stress, active living, and leisure as a contributor to coping with stress. Leisure Sciences, 28(2), 163-180.

Kahneman, D., Krueger, A. B., Schkade, D. A., Schwarz, N., \& Stone, A. A. (2004). A survey method for characterizing daily life experience: The day reconstruction method. Science, 306(5702), 1776-1780.

Kasser, T., \& Ryan, R. M. (1996). Further examining the American dream: Differential correlates of intrinsic and extrinsic goals. Personality and Social Psychology Bulletin, 22(3), 280-287.

Killingsworth, M. A., \& Gilbert, D. T. (2010). A wandering mind is an unhappy mind. Science, 330(6006), 932.

Kivetz, R., \& Keinan, A. (2006). Repenting hyperopia: An analysis of self-control regrets. Journal of Consumer Research, 33(2), 273-282.

Kruglanski, A. W., Fishbach, A., Woolley, K., Bélanger, J. J., Chernikova, M., Molinario, E., \& Pierro, A. (2018). A structural model of intrinsic motivation: On the psychology of means-ends fusion. Psychological Review, 125(2), 165.

Lee, L., Frederick, S., \& Ariely, D. (2006). Try it, you'll like it: The influence of expectation, consumption, and revelation on preferences for beer. Psychological Science, 17(12), 1054-1058.

Lovibond, P. F., \& Lovibond, S. H. (1995). The structure of negative emotional states: Comparison of the depression anxiety stress scales (DASS) with the Beck depression and anxiety inventories. Behavior Research and Therapy, 33(3), 335-343.

Lyubomirsky, S., \& Lepper, H. S. (1999). A measure of subjective happiness: Preliminary reliability and construct validation. Social Indicators Research, 46(2), 137-155.

Malkoc, S. A., \& Tonietto, G. N. (2019). Activity versus outcome maximization in time management. Current Opinion in Psychology, 26, 49-53.

McHoskey, J. W. (1994). Factor structure of the Protestant work ethic scale. Personality and Individual Differences, 17(1), 49-52.

Minkov, M. (2013). Cross-cultural analysis: The science and art of comparing the world's modern societies and their cultures. Sage.

Norton, M. I., \& Gino, F. (2014). Rituals alleviate grieving for loved ones, lovers, and lotteries. Journal of Experimental Psychology: General, 143(1), 266-272.
Perlow, L. A. (1999). The time famine: Toward a sociology of work time. Administrative Science Quarterly, 44(1), 57-81.

Plassmann, H., O'doherty, J., Shiv, B., \& Rangel, A. (2008). Marketing actions can modulate neural representations of experienced pleasantness. Proceedings of the National Academy of Sciences, 105(3), 1050-1054.

Pressman, S. D., Matthews, K. A., Cohen, S., Martire, L. M., Scheier, M., Baum, A., \& Schulz, R. (2009). Association of enjoyable leisure activities with psychological and physical well-being. Psychosomatic Medicine, 71(7), 725.

Radloff, L. S. (1977). The CES-D scale: A self-report depression scale for research in the general population. Applied Psychological Measurement, 1(3), 385-401.

Raghunathan, R., Naylor, R. W., \& Hoyer, W. D. (2006). The unhealthy= tasty intuition and its effects on taste inferences, enjoyment, and choice of food products. Journal of Marketing, 70(4), 170-184.

Ratner, R. K., \& Hamilton, R. W. (2015). Inhibited from bowling alone. Journal of Consumer Research, 42(2), 266-283.

Robinson, J. P., \& Godbey, G. (1998). Trend, gender, and status differences in Americans' perceived stress. Society and Leisure, 21(2), 473-489.

Shiv, B., Carmon, Z., \& Ariely, D. (2005). Placebo effects of marketing actions: Consumers may get what they pay for. Journal of Marketing Research, 42(4), 383-393.

Smeets, P., Whillans, A., Bekkers, R., \& Norton, M. I. (2020). Time use and happiness of millionaires: Evidence from the Netherlands. Social Psychological and Personality Science, 11(3), 295-307.

Thompson, E. R. (2007). Development and validation of an internationally reliable shortform of the positive and negative affect schedule (PANAS). Journal of Cross-Cultural Psychology, 38(2), 227-242.

Tonietto, G. N., \& Barasch, A. (in press). Generating content increases enjoyment by immersing consumers and accelerating perceived time. Journal of Marketing. $10.1177 / 0022242920944388$

Tonietto, G. N., \& Malkoc, S. A. (2016). The calendar mindset: Scheduling takes the fun out and puts the work in. Journal of Marketing Research, 53(6), 922-936.

Van Boven, L., \& Gilovich, T. (2003). To do or to have? That is the question. Journal of Personality and Social Psychology, 85(6), 1193-1202.

Voss, J. (1967). The definition of leisure. Journal of Economic Issues, 1(1-2), 91-106.

Watson, D. (1988). Intraindividual and interindividual analyses of positive and negative affect: Their relation to health complaints, perceived stress, and daily activities. Journal of Personality and Social Psychology, 54(6), 1020-1030.

West, C., Mogilner, C., \& DeVoe, S. E. (2021). Happiness from treating the weekend like a vacation. Social Psychological and Personality Science, 12(3), 346-356.

Whillans, A. V. (2019). Time for happiness: Why the pursuit of money isn't bringing you joy-and what will. Harvard Business Review, 117-124.

Wisman, A., \& Goldenberg, J. L. (2005). From the grave to the cradle: Evidence that mortality salience engenders a desire for offspring. Journal of Personality and Social Psychology, 89(1), 46-61. 